CLINICAL STUDY

\title{
Low prevalence of hypopituitarism after subarachnoid haemorrhage using confirmatory testing and with BMI-specific GH cut-off levels
}

\author{
Chris J Gardner, Mohsen Javadpour ${ }^{1}$, Catherine Stoneley ${ }^{1}$, Mani Purthuran ${ }^{1}$, Shubhabrata Biswas ${ }^{1}$, \\ Christina Daousi, Ian A MacFarlane and Daniel J Cuthbertson \\ University Department of Obesity and Endocrinology, 3rd Floor Clinical Sciences Centre, Aintree University Hospital NHS Foundation Trust, University \\ Hospital Aintree, Longmoor Lane, Liverpool L9 7AL, UK and ${ }^{1}$ Departments of Neurosurgery and Radiology, Walton Centre for Neurology and \\ Neurosurgery NHS Foundation Trust, Liverpool, UK \\ (Correspondence should be addressed to D J Cuthbertson; Email: daniel.cuthbertson@liverpool.ac.uk)
}

\begin{abstract}
Objective: Hypopituitarism following subarachnoid haemorrhage (SAH) has been reported to be a frequent occurrence. However, there is considerable heterogeneity between studies with differing patient populations and treatment modalities and most importantly employing differing endocrine protocols and (normal) reference ranges of $\mathrm{GH}$. We aimed to examine prospectively a cohort of SAH survivors for development of hypopituitarism post-SAH using rigorous endocrine testing and compare GH response to glucagon stimulation with a cohort of healthy controls of a similar BMI.

Design and methods: Sixty-four patients were investigated for evidence of hypopituitarism 3 months post-SAH with 50 patients tested again at 12 months. Glucagon stimulation testing (GST), with confirmation of deficiencies by GHRH/arginine testing for GH deficiency (GHD) and short synacthen testing for ACTH deficiency, was used. Basal testing of other hormonal axes was undertaken.

Results: Mean age of patients was $53 \pm 11.7$ years and mean BMI was $27.5 \pm 5.7 \mathrm{~kg} / \mathrm{m}^{2}$. After confirmatory testing, the prevalence of hypopituitarism was $12 \%$ (GHD $10 \%$, asymptomatic hypocortisolaemia $2 \%$ ). There was no association between hypopituitarism and post-SAH vasospasm, presence of cerebral infarction, Fisher grade, or clinical grading at presentation. There was a significant correlation between BMI and peak GH to glucagon stimulation in both patients and controls.

Conclusions: Identification of 'true' GHD after SAH requires confirmatory testing with an alternative stimulation test and application of BMI-specific cut-offs. Using such stringent criteria, we found a prevalence of hypopituitarism of $12 \%$ in our population.
\end{abstract}

European Journal of Endocrinology 168 473-481

\section{Introduction}

The true prevalence of anterior hypopituitarism after aneurysmal subarachnoid haemorrhage (SAH) remains debatable. A number of studies, often incorporating patients with both SAH and traumatic brain injury (TBI), have concluded that hypopituitarism is common in this patient group $(1,2,3,4,5)$, with a systematic review by Schneider et al. in 2007 (6) concluding that hypopituitarism is present in $47 \%$ of patients in the chronic phase after SAH. In contrast, Klose et al. (7), evaluating 61 patients prospectively, concluded that SAH was uncommon having failed to identify a single case. Lammert et al. (8) have recently confirmed a prevalence of hypopituitarism lower than previously thought, although in this selected cohort not all patients underwent dynamic testing. Currently, a number of endocrine societies have recommended that all patients should undergo evaluation of anterior pituitary function after SAH $(9,10)$.

There are limitations to the current literature, which may explain the widely ranging prevalence figures of hypopituitarism post-SAH, with a variety of dynamic tests using differing normal cut-off values to determine GH deficiency (GHD) and a lack of confirmatory testing with a repeat or an alternative stimulation test to demonstrate GHD. Other confounding factors include assessments at varying time points post-injury and a failure to account for the effects of obesity on $\mathrm{GH}$ response to stimulation testing (11), where obese patients are more likely to receive a falsely positive diagnosis of GHD. Finally, treatment modalities have changed in recent years with most patients now treated by endovascular coiling compared with craniotomy and clipping (12), which may reduce the severity of the pituitary insult. 
The aim of this study was to assess the prevalence and progression of anterior pituitary hormone deficiencies, and in particular GHD, with prospective evaluation at 3 and 12 months post-SAH, using confirmatory testing with an alternative dynamic test and accounting for the confounding effects of obesity on $\mathrm{GH}$ secretion. We hypothesised that by adopting such a rigorous approach, the prevalence of post-SAH hypopituitarism would be lower than previously reported.

\section{Materials and methods}

\section{Patient recruitment}

Between November 2008 and December 2009, we monitored the presentation and progress of 147 patients with a diagnosis of SAH admitted to the Walton Centre for Neurology and Neurosurgery, a tertiary neurosurgical referral centre in Liverpool, UK. The outcomes of these patients are shown in Fig. 1. Eleven patients $(7.3 \%)$ died in the Neurological Intensive Care Unit and nine (6\%) died following discharge from the hospital and before any endocrine follow-up. The remaining 127 patients were invited to attend for endocrine follow-up at University Hospital Aintree, of which 85 patients attended. Twenty-one of these had incomplete evaluation for a variety of reasons (needle-phobia, declined consent for dynamic function

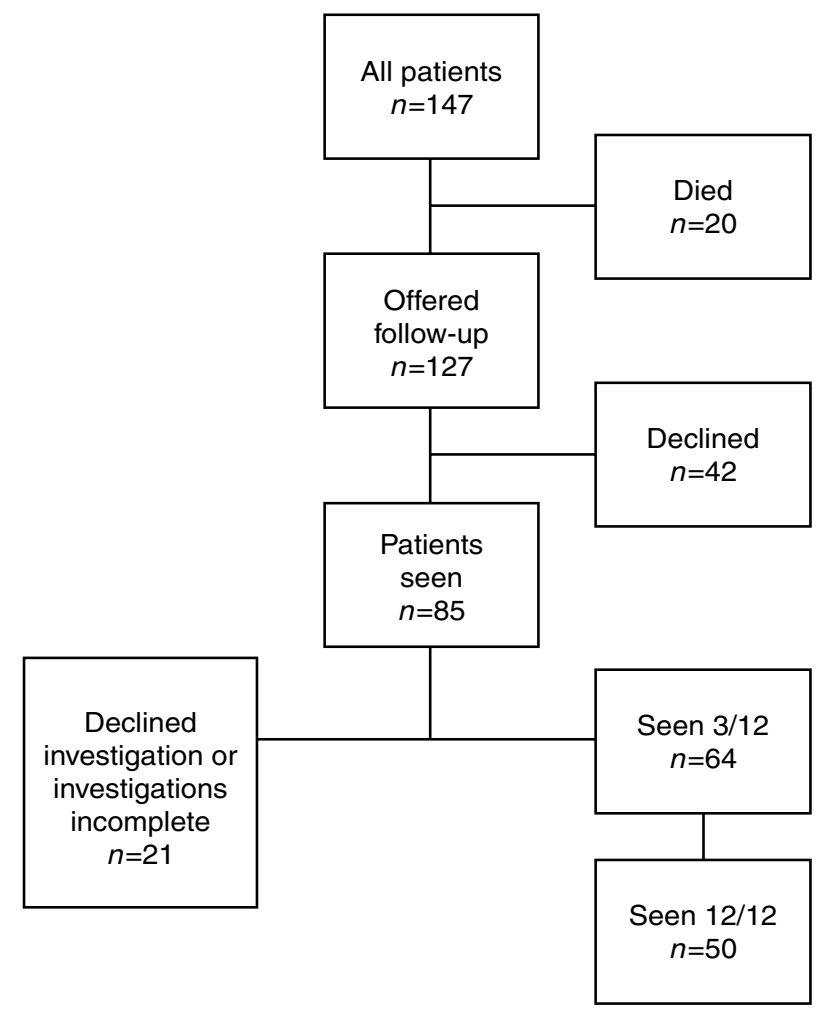

Figure 1 Patient flow diagram demonstrating outcomes of 147 patients admitted with a diagnosis of $\mathrm{SAH}$. testing or declined further follow-up due to lack of symptoms). Thus, 64 patients $(50 \%)$ underwent complete evaluation of which three had a nonaneurysmal SAH. Fifty of these patients were evaluated both at 3 and 12 months post-SAH. In order to ensure that there was no selection bias, baseline characteristics of non-participants were also recorded where available (Table 1).

In order to evaluate the effect of BMI on dynamic function, 14 controls with a range of BMI also underwent dynamic function testing by glucagon stimulation test (GST). Exclusion criteria included known pituitary disease, or history of TBI or SAH. Control participants were recruited by local advert. The study was approved by the local research ethics committee.

\section{Clinical protocols}

Patients were assessed prospectively on two occasions, at 3 and 12 months post-SAH (or as close as possible to these time points as was practical). An investigation algorithm is shown in Fig. 2. All patients and volunteers underwent clinical evaluation, testing of basal pituitary hormones and dynamic function testing using the GST. All patients with biochemical evidence of cortisol insufficiency or severe GHD underwent confirmatory testing by an alternative method (short synacthen testing (SST) and GHRH + arginine test).

\section{Anthropometric and quality of life questionnaires}

Body weight was measured to the nearest $0.1 \mathrm{~kg}$ wearing light clothing on TANITA scales (Tanita BC420, Dolby Medical, Stirling, UK) at each visit and height measured to the nearest $0.5 \mathrm{~cm}$ at the initial visit. Quality of life (QOL) was assessed at each visit using a validated questionnaire developed for use specifically in GHD (QOL in adult GHD assessment, QOL-AGHDA) (13).

\section{Clinical and radiological markers of severity of SAH}

Clinical severity was independently graded based on the clinical history and examination findings at presentation according to the World Federation of Neurosurgical Societies (WFNS) scoring system (14). Admission CT brain scans were reviewed by one of two radiologists who were blinded to the clinical condition of the patient and Fisher scale recorded (15) (Table 1). The number of aneurysms, size and location of aneurysm(s), treatment with ionotropes and medication use were also recorded. In addition, episodes of delayed ischaemic neurological deficit (DIND) (vasospasm) and presence of hydrocephalus were recorded. Follow-up MRI scans at 6 months were reviewed for evidence of infarction. 
Table 1 Subject characteristics of $64^{a}$ patients with subarachnoid haemorrhage. Numbers (and percentages) demonstrate the distribution of WFNS scores and Fisher scores.

\begin{tabular}{|c|c|c|}
\hline Parameter & $\begin{array}{l}\text { Participants } \\
(n=64)\end{array}$ & $\begin{array}{l}\text { Non-participants } \\
(n=63)\end{array}$ \\
\hline Age & $53.7 \pm 11.6$ & $57.5 \pm 13.5$ \\
\hline $\mathrm{BMI}$ & $27.5 \pm 5.7$ & - \\
\hline Gender (M:F) & $25: 39$ & $20: 43$ \\
\hline \multicolumn{3}{|l|}{ Fisher grade } \\
\hline 1 & $3(5 \%)$ & $2(4 \%)$ \\
\hline 2 & $12(21 \%)$ & $2(4 \%)$ \\
\hline 3 & $22(38 \%)$ & $14(28 \%)$ \\
\hline 4 & $21(36 \%)$ & $32(64 \%)$ \\
\hline Unknown & 6 & 13 \\
\hline \multicolumn{3}{|c|}{ World Federation of Neurological Surgeons Score } \\
\hline 1 & 49 (78\%) & $27(62 \%)$ \\
\hline 2 & $10(16 \%)$ & $10(23 \%)$ \\
\hline 3 & 0 & $2(5 \%)$ \\
\hline 4 & $3(5 \%)$ & $3(7.5 \%)$ \\
\hline 5 & $1(1 \%)$ & $1(2.5 \%)$ \\
\hline Unknown & 1 & 20 \\
\hline Hydrocephalus & $8(12.5 \%)$ & - \\
\hline Delayed ischaemic neurological deficit & $14(22 \%)$ & - \\
\hline \multicolumn{3}{|l|}{ Aneurysm size $(n=55)$} \\
\hline$\leq 10 \mathrm{~mm}$ & 41 & - \\
\hline $11-25 \mathrm{~mm}$ & 14 & - \\
\hline \multicolumn{3}{|l|}{ Aneurysm treatment $(n=64)$} \\
\hline Endovascular coil & 60 & \\
\hline Clipping & 1 & \\
\hline None & 3 (all non-aneurysmal) & \\
\hline \multicolumn{3}{|l|}{ Aneurysm location } \\
\hline Middle cerebral artery & 9 & \\
\hline Basilar artery & 8 & \\
\hline Posterior communicating artery & 19 & \\
\hline Anterior communicating artery & 15 & \\
\hline Pericallosal artery & 2 & \\
\hline Anterior cerebral artery & 3 & \\
\hline Other site & 5 & \\
\hline
\end{tabular}

${ }^{\text {a}}$ Fisher score unavailable in six patients due to transfer in from other hospitals.

\section{Biochemical tests}

Following a detailed history and physical examination, all patients underwent basal pituitary hormone testing including IGF1, TSH, free thyroxine $\left(\mathrm{FT}_{4}\right)$, free triiodothyronine $\left(\mathrm{FT}_{3}\right)$, LH, $\mathrm{FSH}$, oestradiol, testosterone and prolactin measurements and a GST for assessment of $\mathrm{GH}$ and cortisol reserve. $\mathrm{GH}$ measurements were made on a Siemens Immulite 2000 using a Solid phase 2-site chemiluminescent immunometric assay (analytical sensitivity $0.03 \mathrm{mIU} / \mathrm{l}, \mathrm{CV} 4.2-6.6 \%$ ). Conversion factor was $1 \mu \mathrm{g} / \mathrm{l}$ to $3 \mathrm{mIU} / \mathrm{l}$. The investigation protocol is shown in Fig. 2.

\section{Glucagon stimulation testing}

Following an overnight fast, an indwelling venous cannula was inserted, and blood was drawn for baseline $\mathrm{GH}$, cortisol and glucose measurements. Glucagon (GlucaGen, Novonordisk, Copenhagen, Denmark) $1 \mathrm{mg}$ (1.5 mg for patients with weight $>90 \mathrm{~kg}$ ) (16) was administered subcutaneously following which blood for cortisol, GH and glucose was drawn at 90, 120, 150,
180 and $210 \mathrm{~min}$. All patients with an inadequate $(<500 \mathrm{nmol} / \mathrm{l})$ cortisol response to glucagon underwent standard dose $(250 \mu \mathrm{g})$ SST to confirm cortisol deficiency at 12 months; however, patients with a peak cortisol $<350$ or $<500 \mathrm{nmol} / \mathrm{l}$ with symptoms (such as lethargy) at 3 months underwent immediate SST - all were normal and no patient required hydrocortisone replacement between 3 and 12 months.

\section{Synacthen tests}

Following insertion of an indwelling venous cannula, blood was drawn for cortisol measurement, following which Synacthen (Alliance Pharmaceuticals, Chippenham, Wilts, UK) $250 \mu \mathrm{g}$ was given intravenously. Blood for cortisol was drawn 30 min later.

\section{GHRH/arginine tests}

Patients with a GH response to glucagon stimulation $<3 \mu \mathrm{g} / \mathrm{l}$ underwent GHRH/arginine testing; following an overnight fast, an i.v. cannula was inserted and blood 


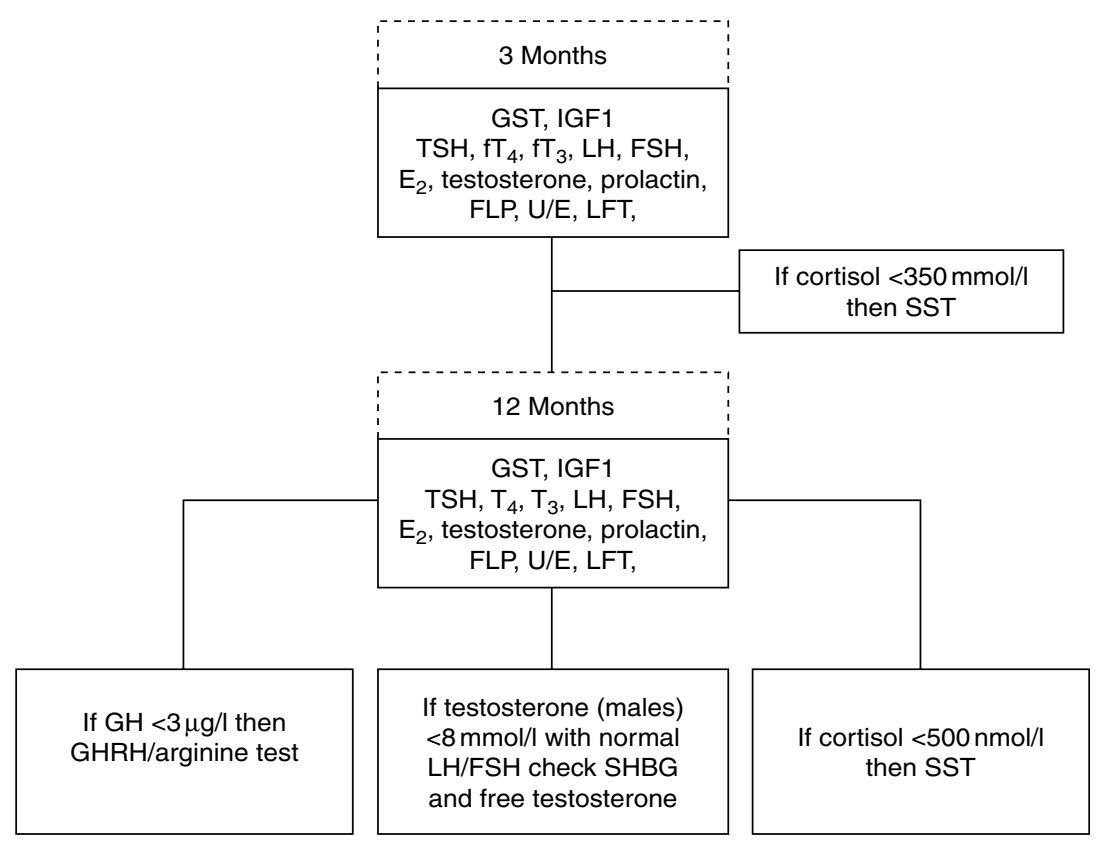

Figure 2 Investigation algorithm for hypopituitarism in 64 patients with SAH. GST, glucagon stimulation test; $E_{2}$, ethinyloestrodiol; FLP, fasting lipid profile; U/E, urea and electrolytes; LFT, liver function tests; SST, short synacthen test; SHBG, sex hormone binding globulin; IGF1, insulin-like growth factor 1 , cortisol, peak cortisol on dynamic function testing. was drawn for $\mathrm{GH}$ measurement. GHRH (Ferring, St-Prex, Switzerland) $(1 \mu \mathrm{g} / \mathrm{kg}$ to a maximum of $200 \mu \mathrm{g}$ ) was given intravenously following which the patient received an infusion of arginine $10 \%$ solution $(0.5 \mathrm{~g} / \mathrm{kg}$ to a maximum of $30 \mathrm{~g})$. Samples for $\mathrm{GH}$ were drawn 30, 60, 90 and 120 min after the start of the test.

\section{Definition of biochemical hormone deficiencies}

Severe GHD was defined as peak GH $<3 \mu \mathrm{g} / \mathrm{l}$ to glucagon stimulation. The response to GHRH/arginine was stratified by BMI (cut-off for severe GHD: $\mathrm{GH}<11.5 \mu \mathrm{g} / \mathrm{l}$ for BMI $<25 \mathrm{~kg} / \mathrm{m}^{2},<8 \mu \mathrm{g} / \mathrm{l}$ for BMI $25-30 \mathrm{~kg} / \mathrm{m}^{2}$ and $<4.2 \mu \mathrm{g} / \mathrm{l}$ for BMI $>30 \mathrm{~kg} / \mathrm{m}^{2}$ ) (17). Cortisol insufficiency was defined as a peak cortisol $<500 \mathrm{nmol} / \mathrm{l}$ to both glucagon and synacthen testing (18). Gonadotrophin deficiency in males was defined as an early morning testosterone of $<8.5 \mathrm{nmol} / \mathrm{l}$ (lower limit of normal range for assay) on two occasions with gonadotrophins within the normal range, and confirmation testing at 12 months also required a free testosterone concentration below the normal range in addition to the above. In females, gonadotrophin deficiency was defined as amenorrhoea with a low oestradiol level and gonadotrophins within the normal range, or a low oestradiol with premenopausal gonadotrophins in post-menopausal women. Secondary hypothyroidism was defined as a $\mathrm{FT}_{4}$ of $<8 \mathrm{pmol} / \mathrm{l}$ (lower limit of normal range for assay) with a TSH of $<4.5 \mathrm{mU} / \mathrm{l}$ (upper limit of normal range). Primary hypothyroidism was defined as a $\mathrm{FT}_{4}<8 \mathrm{pmol} / \mathrm{l}$ with a TSH above the normal range $(4.5 \mathrm{mU} / \mathrm{l})$.

\section{Statistical analysis}

Results are expressed as mean (s.D.) unless otherwise stated. Smaller subgroup data are expressed as median (range). Data analysis was performed using SPSS 17.0 for Windows (SPSS). $P<0.05$ (two tailed) was considered statistically significant.

\section{Results}

\section{Clinical characteristics}

Sixty-four patients were clinically reviewed at 3 months, of which 50 completed follow-up at 12 months. No patient had known neuroendocrine disease before the pathological event. No patient was receiving glucocorticoid replacement during the course of his or her follow-up. Clinical characteristics of these patients including treatment are summarised in Table 1.

Of the 64 patients completing the initial testing, 25 (39\%) were males and $39(61 \%)$ were females, mean age was $53.7 \pm 11.6$ years and mean BMI was $27.5 \pm 5.7 \mathrm{~kg} / \mathrm{m}^{2}$. Thirty-nine $(61 \%)$ patients were either current or recent smokers. All patients underwent four-vessel angiography: in three patients, however, no aneurysm or arteriovenous malformation was detected. Of the 61 patients with aneurysms identified, $17(27 \%)$ patients had more than one aneurysm. Additional surgery was required in nine cases (External Ventricular Drain insertion for hydrocephalus in eight $(12.5 \%)$ patients, haematoma evacuation in one patient). Fourteen $(22 \%)$ patients had evidence of DIND (radiological evidence only in two 
Table 2 Prevalence of individual hormone deficiencies in 64 patients tested at 3 months and 50 patients tested at 12 months together with prevalence after confirmatory testing. Note that five (8\%) and seven patients (14\%) had multiple deficiencies at 3 and 12 months respectively.

\begin{tabular}{llll}
\hline & \multicolumn{2}{c}{ Glucagon stimulation testing } & \multicolumn{2}{c}{$\begin{array}{l}\text { GHRH/arginine+synacthen } \\
\text { testing } \\
12 \text { months }(n=50)\end{array}$} \\
\cline { 2 - 4 } & 3 months $(n=64)$ & 12 months $(n=50)$ & $6(12 \%)$ \\
Hypopituitarism (any hormone) & $29(45 \%)$ & $25(50 \%)$ & $5(10 \%)$ \\
GHD & $13(20 \%)$ & $11(22 \%)$ & $1(2 \%)$ \\
Hypocortisolism & $18(21 \%)$ & $20(40 \%)$ & 0 \\
Hypogonadism & $5(8 \%)$ & 0 & 0 \\
Hypothyroidism & 0 & 0 & 0 \\
Hyperprolactinaemia & 0 & 0 & 0 \\
\hline
\end{tabular}

patients) during the acute recovery period. Eight patients suffered with hydrocephalus. Three patients had evidence of infarction at follow-up MRI scanning, frontal lobe in one patient and lacunar infarction in two other patients. Median duration of hospital stay was 12 days (range $4-130$ days).

\section{Anterior pituitary function}

The results of pituitary function testing are shown in Table 2. Overall, at 12 months, the prevalence of hypopituitarism was $12 \%$ consisting of isolated GHD in $10 \%$ and asymptomatic hypocortisolaemia (not requiring treatment) in a single patient (2\%). Likewise, there was no change in BMI in the cohort as a whole during this time (3 months $27.4 \pm 5.7 \mathrm{~kg} / \mathrm{m}^{2}, 12$ months $\left.27.8 \pm 5.3 \mathrm{~kg} / \mathrm{m}^{2}, P=0.73\right)$.

Patients with hypopituitarism post-SAH were significantly younger $(45(27,50)$ vs $54(20,77), P=0.02)$; however, there was no difference in BMI either shortly after diagnosis or at the time of re-testing at 12 months (see Table 3). Significantly, however, hypopituitary patients had overall demonstrated weight loss, while other patients had marginal weight gain. No patients with hypopituitarism had hydrocephalus or required inotropes. Only one patient in the hypopituitary group had evidence of DIND. There was no association between DIND or requirement for surgery and subsequent development of hypopituitarism. The three patients with infarction had normal pituitary function. There was no difference in the distribution of Fisher or WFNS grades between the groups.

GH axis There was no significant difference in the prevalence of GHD at 3 and 12 months based on GST. Five patients $(8 \%)$ and seven patients $(14 \%)$ had multiple deficiencies at 3 and 12 months respectively based on the GST. There was a significant reduction in the prevalence when a second confirmatory test using BMI-specific cut-offs was employed, and no multiple deficiencies were confirmed. There was no difference in mean IGF1 between patients with or without hypopituitarism (Table 3).

Thyroid axis There was no significant difference in TSH between the groups at either 3 or 12 months. A single case of apparent secondary hypothyroidism was detected; however, the patient was taking phenytoin for seizures related to the SAH. Thyroid function subsequently normalised. Two incidental cases of primary hypothyroidism were discovered; patients were treated and were biochemically and clinically euthyroid before pituitary function testing.

Table 3 Comparison between patients diagnosed with hypopituitarism on confirmatory testing at 12 months and those patients with normal pituitary function.

\begin{tabular}{llll}
\hline Parameter & $\begin{array}{l}\text { Hypopituitarism at } \\
\mathbf{1 2} \text { months }(n=6)\end{array}$ & $\begin{array}{l}\text { Normal pituitary at } \\
\mathbf{1 2} \text { months }(n=44)\end{array}$ & $\boldsymbol{P}$ value \\
\hline Age & $45(27,50)$ & $54.6(20,77)$ & 0.02 \\
Gender $(\mathrm{M} / \mathrm{F})$ & $6 / 0$ & $14 / 30$ & 0.002 \\
BMI 3 months $\left(\mathrm{kg} / \mathrm{m}^{2}\right)$ & $28.4(24.2,36.3)$ & $26.6(18.3,43.9)$ & 0.52 \\
BMl 12 months $\left(\mathrm{kg} / \mathrm{m}^{2}\right)$ & $27.5(23.2,36.7)$ & $27.7(18.7,47.1)$ & 0.96 \\
Change in BMI $\left(\mathrm{kg} / \mathrm{m}^{2}\right)$ & $-0.2(-1,0.4)$ & $0.5(-3.4,3.5)$ & 0.04 \\
Basal cortisol 3 months (nmol/l) & $202(178,449)$ & $458(146,760)$ & 0.008 \\
Basal cortisol 12 months (nmol/l) & $256(133,603)$ & $348(192,556)$ & 0.17 \\
IGF1 3 months (nmol/l) & $18(14,32)$ & $16.5(3,34)$ & 0.80 \\
IGF1 12 months (nmol/l) & $22(10,29)$ & $17(4,51)$ & 0.90 \\
Prolactin 3 months $(\mathrm{mU} / \mathrm{l})$ & $105(71,163)$ & $116(71,163)$ & 0.94 \\
Prolactin 12 months $(\mathrm{mU} / \mathrm{l})$ & $106(95,117)$ & $113(48,286)$ & 0.64 \\
QOL-AGHDA 3 months & $17(6,23)$ & $11(0,25)$ & 0.10 \\
QOL-AGHDA 12 months & $16(3,25)$ & $10(0,25)$ & 0.10 \\
\hline
\end{tabular}


Adrenal axis A single patient failed to mount a cortisol response $>500 \mathrm{nmol} / \mathrm{l}$ at 12 months. Peak cortisol to synacthen was $473 \mathrm{nmol} / \mathrm{l}$; however, the patient was asymptomatic without other pituitary deficits and therefore did not require treatment.

Despite the low prevalence of confirmed adrenal insufficiency on stimulation testing, basal cortisol was significantly lower in the hypopituitary group at 3 months. Although this difference remained at 12 months, this was not statistically significant.

Gonadotrophin axis No cases of female hypogonadism were detected. Five male patients were found to have low testosterone in the presence of normal gonadotrophins. Two of these patients had clinical symptoms compatible with androgen deficiency (impotence, loss of libido) and received androgen replacement between 6 and 12 months after repeat testing confirmed the results. In both these patients, however, this resolved spontaneously by 12 months and replacement was discontinued. The remaining three patients were asymptomatic and were found to have a low sex hormone binding globulin (SHBG) presumed secondary to obesity and a normal free testosterone on 12-month confirmatory testing.

Prolactin There was no significant difference in prolactin levels between patients at 3 and 12 months or patients with and without hypopituitarism. No cases of hyperprolactinaemia were recorded.

QOL scores QOL was impaired at both 3 and 12 months as demonstrated by the QOL-AGHDA score in which a score of $>10 / 25$ indicates significant impairment of QOL (13). There was no significant change in mean QOL-AGHDA score over the period of follow-up (3 months $11.1 \pm 7.6,12$ months $10.4 \pm 7.1, P=0.25$ ). There was no significant difference in QOL-AGHDA scores between patients with or without hypopituitarism (Table 3), although patients with hypopituitarism had a tendency towards higher scores. QOL scores at 3 and 12 months were not correlated with peak GH or basal cortisol at either time point.

\section{Effect of BMI on GST}

SAH cohort $(\mathbf{n}=64)$ There was a significant correlation between peak GH to GST and BMI; $R=-0.629$, $P<0.0001$ (Fig. 3). In stepwise linear regression in which the variables age, gender, need for inotropes, presence of hydrocephalus, WFNS score and Fisher grade were entered, BMI and inotropes were deemed significant $(R=0.581$, BMI $P \leq 0.001$, inotropes, $P=0.003)$. At 12 months, the only significant variable affecting peak $\mathrm{GH}$ in linear regression analysis was BMI at 12 months $(R=-0.43, P=0.003)$. There was no
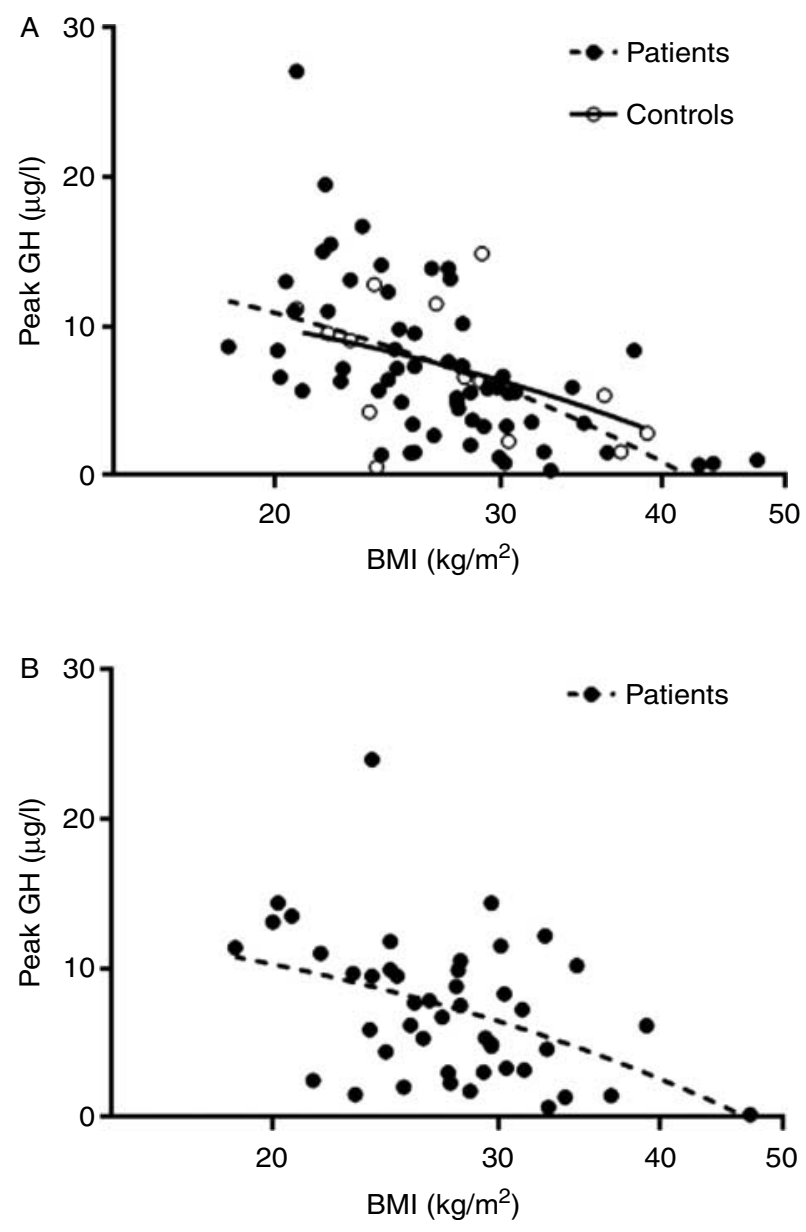

Figure 3 Peak GH response vs BMI (logarithmically transformed) for patients and controls following $\mathrm{SAH}$. Panel A demonstrates results at 3 months $(n=64)$ together with 14 healthy controls. Panel B demonstrates results at 12 months $(n=50)$, showing a strong negative correlation $(r=-0.569(-0.7$ to -0.35$)$, $P<0.0001 ; r=-0.43(-0.64$ to -0.16$) ; P<0.005)$.

correlation between peak cortisol and BMI $(R=-0.1$, $P=0.42)$.

Control population $(\mathbf{n}=14)$ The median (range) age of the controls was $47.5(34,62)$ years with a BMI of $27.4(20.8,39) \mathrm{kg} / \mathrm{m}^{2}$ with IGF1 of $17.5(10,35)$ nmol/l. Peak GH was $6.46(0.56,14.9) \mu \mathrm{g} / \mathrm{l}$ and peak cortisol was $540(271,998) \mathrm{nmol} / \mathrm{l}$. Of the 14 healthy controls recruited, four participants would have been classed as GH deficient (peak GH $<3 \mu \mathrm{g} / \mathrm{l}$ ). Three of these participants had a BMI $>30 \mathrm{~kg} / \mathrm{m}^{2}$. There was a non-significant correlation between BMI and peak GH (Spearman correlation coefficient $R=-0.44, P=0.1$, Fig. 3). There was no correlation between IGF1 level and peak GH. Six controls would be classed as having an inadequate cortisol response $(<500 \mathrm{nmol} / \mathrm{l})$ on the basis of the GST, with the lowest cortisol peak being $271 \mathrm{nmol} / \mathrm{l}$, but with a subsequently normal synacthen test. 


\section{Discussion}

We have demonstrated that with the application of rigorous diagnostic criteria, using multiple dynamic function tests and BMI-specific cut-offs to define GHD, hypopituitarism occurs in only $12 \%$ of patients 12 months post-SAH. Our observed prevalence is lower than the range $(37.5-55 \%)$ reported by the systematic review by Schneider et al. (6); however, it is comparable to the results of the recent study by Lammert et al. (8) that found a prevalence of GHD of $10 \%$.

There are two significant differences between the current study and previous studies. The first difference relates to the use of multiple and confirmatory $\mathrm{GH}$ provocation tests. The importance of confirmatory testing in reliably diagnosing GHD and cortisol deficiency has already been highlighted in studies examining hypopituitarism in TBI (19). Klose et al. (7) assessed 61 patients for GHD using the insulin tolerance test (ITT), or if contra-indicated, the GHRH-arginine test. In cases where GHD was demonstrated, a confirmatory test was performed. With this approach, surprisingly, the authors did not identify a single case of hypopituitarism. Their approach is, however, consistent with the findings of Lissett $e$ al. (20) who demonstrated that a single GH provocation test can only reliably diagnose GHD in patients with two or three additional pituitary hormone deficits. For these reasons, we used two different $\mathrm{GH}$ provocation tests to confirm the diagnosis of GHD in all patients as none of our patients had multiple pituitary deficiencies. The second significant confounding factor affecting the outcome of endocrine testing in many of the earlier studies is a failure to account for the effects of obesity on $\mathrm{GH}$ secretion. Obesity has been clearly associated with impaired GH secretion: for each unit increase in BMI, there is a $6 \%$ reduction in the daily $\mathrm{GH}$ secretion rate (21). This impairment is also evident in patients at risk for pituitary function deficit and thus is reflected in the results of a variety of $\mathrm{GH}$ provocation tests with negative correlation of GH peak with BMI $(11,17,22,23)$, including the ITT $(11,24)$. BMI-specific GH cut-off values to diagnose GHD using the GHRH-arginine test have been published (17). As yet, however, there have been no analyses of BMI-specific cut-offs to diagnose GHD when other stimulation tests are used.

Our Endocrine Unit uses the GST as the first-line GH provocation test (16), which has been validated previously $(25,26)$ and has been shown to be equivalent to the ITT $(27,28)$. The Endocrine Society in its recent guidelines acknowledged the role of the GST for the diagnosis of GHD, particularly in the face of the recent shortage of GHRH (29) and in cases where the ITT may be contra-indicated $(9,10)$. Gomez et al., who evaluated the GST in healthy controls, found that none of their 46 volunteers failed to achieve a $\mathrm{GH}$ response $<3 \mu \mathrm{g} / \mathrm{l}$; however, the population used was lean. They did, however, note a significant correlation between BMI and peak GH response (30). We have demonstrated a negative correlation between peak GH and BMI in both healthy controls and in SAH patients; patients and healthy controls with a BMI $>30 \mathrm{~kg} / \mathrm{m}^{2}$ frequently failed to achieve a peak GH level $>3 \mu \mathrm{g} / \mathrm{l}$. Assuming that our study conclusions had been based only on the outcome of a single test (the GST), without consideration of BMI or a second confirmatory test, the reported prevalence of hypopituitarism would have been very different, at $50 \%$, broadly in line with the results of the early studies. This would suggest that the GST should not be used in isolation for diagnosis of hypopituitarism following SAH. Instead, using strict diagnostic criteria, the prevalence of GHD was only $10 \%$.

The second possible explanation for our much lower prevalence of neuroendocrine dysfunction may relate to the population studied. By offering follow-up to all SAH survivors, we had a large proportion of more favourable grade SAH patients; however, Klose et al. had more higher grade patients, and Lammert et al. only included patients with Fisher score 3/4, yet both groups found a prevalence similar or lower than ourselves. Our rate of vasospasm was lower than Lammert et al. and comparable to Klose et al.; however, we had the greatest proportion of patients treated by endovascular coiling which may have been a significant factor. Kreitschmann-Andermahr et al. (31) had speculated that open surgery may be associated with a higher incidence of hypopituitarism, and Bellebaum et al. (32) had found a higher incidence of neuropsychological morbidity in patients who underwent clipping vs coiling.

One of the main strengths of our study is that our cohort of patients is a representative sample of all SAH patients, with all surviving patients invited and encouraged to undergo evaluation at 3 and 12 months post-SAH, including patients with significant disability. Participants and non-participants are of similar age with a similar severity of SAH (according to WFNS scores at presentation). While caution must be exhibited in using cut-off values from alternative assays, we have used commercial assays with good standardisation data. Furthermore, the similar prevalence of GHD on GST compared with other studies using the GST alone is further reassurance of the appropriateness of this method.

We have also demonstrated that patients with confirmed hypopituitarism have significantly lower basal cortisol levels at 3 months and a tendency for lower levels at 12 months, although they have acceptable peak cortisol responses following dynamic testing of the hypothalamic-pituitary-adrenal axis. These patients also tended to have lower QOL scores (QOL-AGHDA); however, this was not statistically significant. These findings of subtle defects of cortisol production, not apparent on stimulation testing, may suggest that disturbances in the circadian rhythm may be present as noted by Osterman (33) and lends support 
to the concept that these patients suffer pituitary insufficiency, rather than overt hypopituitarism, as is normally found in other causes of hypopituitarism. While these disturbances are not likely to lead to acute adrenal insufficiency, they may be responsible for the often-disabling lethargy seen in these patients. However, given the complex interplay of both age and BMI on normal adrenal responses and ACTH sensitivity (34), these changes could simply represent normal physiological variance. This aspect certainly merits further investigation, and evaluation of the hypothalamopituitary-adrenal axis with 24-h cortisol concentrations and diurnal variability may be informative.

With such a low prevalence, we were unable to identify any clinical factors that may predict hypopituitarism. Kelly et al. (3) had suggested the presence of clinical vasospasm as a possible aetiological factor; however, only one of our patients with hypopituitarism had suffered this complication. Lammert et al. (8) had also found a link between early hypogonadism and vasospasm. We did not find this; however, the number of cases of vasospasm in that cohort was approximately double the number in our cohort. Likewise, we found no link with the presence of hydrocephalus in our study. Crompton (35) had noted hypothalamic damage due to macro and micro haemorrhage in post-mortem specimens from patients with SAH. Three of our patients had radiological evidence of infarction on follow-up scanning; however, this was not associated with hypopituitarism. Unusually, in this study, we included three patients without an identifiable aneurysm (nonaneurysmal SAH), two of whom were found to have hormonal insufficiencies and this has previously been reported (36); however, recent studies have not included this patient group. This group may warrant further study.

In conclusion, we have demonstrated a prevalence of hypopituitarism in SAH of $12 \%$ after 12 months of follow-up, consisting of isolated GHD in 10\% and asymptomatic hypocortisolaemia in $2 \%$. We did not identify any predictive factors for the development of hypopituitarism; however, we have demonstrated evidence of subtle defects in the hypothalamo-pituitary axis that may suggest evidence of pituitary dysfunction. We therefore believe that universal screening for the presence of hypopituitarism is justified and that this should be performed at least 12 months after the SAH, when potentially reversible pituitary dysfunction has resolved. Given the effect that confounders, such as obesity, have on dynamic testing for $\mathrm{GH}$ in particular, reference ranges that take into account obesity should be used, and in the presence of isolated deficits, confirmatory testing should be undertaken. Given the findings of Karaca et al. (37) that new GHD cases may evolve up to 3 years post-insult, and our own experience of evolving GHD (38), patients with ongoing symptoms suggestive of hypopituitarism may benefit from rescreening despite previously normal results.

\section{Declaration of interest}

The authors declare that there is no conflict of interest that could be perceived as prejudicing the impartiality of the research reported.

\section{Funding}

The study was funded jointly by an investigator-initiated research award to D J Cuthbertson from Pfizer and by the medical research charity, Weight Matters.

\section{Author contribution statement}

C J Gardner, C Stoneley, M Javadpour, I A MacFarlane and D J Cuthbertson conceived and designed the study. C J Gardner carried out investigations and drafted the manuscript. M Purthuran and S Biswas reviewed and interpreted radiology images. C Daousi, M Javadpour, I A MacFarlane and D J Cuthbertson reviewed and revised the manuscript for intellectual content. All authors approved the final manuscript.

\section{References}

1 Aimaretti G, Ambrosio MR, Di Somma C, Gasperi M, Cannavo S, Scaroni C, Fusco A, Del Monte P, De Menis E, Faustini-Fustini M et al. Residual pituitary function after brain injury-induced hypopituitarism: a prospective 12-month study. Journal of Clinical Endocrinology and Metabolism 200590 6085-6092. (doi:10.1210/jc.2005-0504)

2 Dimopoulou I, Kouyialis AT, Tzanella M, Armaganidis A, Thalassinos N, Sakas DE \& Tsagarakis S. High incidence of neuroendocrine dysfunction in long-term survivors of aneurysmal subarachnoid hemorrhage. Stroke 200435 2884-2889. (doi:10.1161/01.STR.0000147716.45571.45)

3 Kelly DF, Gonzalo IT, Cohan P, Berman N, Swerdloff R \& Wang C. Hypopituitarism following traumatic brain injury and aneurysmal subarachnoid hemorrhage: a preliminary report. Journal of Neurosurgery 200093 743-752. (doi:10.3171/jns.2000.93.5.0743)

4 Kreitschmann-Andermahr I. Subarachnoid hemorrhage as a cause of hypopituitarism. Pituitary 20058 219-225. (doi:10.1007/ s11102-006-6044-2)

5 Tanriverdi F, Dagli AT, Karaca Z, Unluhizarci K, Selcuklu A, Casanueva FF \& Kelestimur F. High risk of pituitary dysfunction due to aneurysmal subarachnoid haemorrhage: a prospective investigation of anterior pituitary function in the acute phase and 12 months after the event. Clinical Endocrinology 200767 931-937. (doi:10.1111/j.1365-2265.2007.02989.x)

6 Schneider HJ, Kreitschmann-Andermahr I, Ghigo E, Stalla GK \& Agha A. Hypothalamo-pituitary dysfunction following traumatic brain injury and aneurysmal subarachnoid hemorrhage: a systematic review. Journal of the American Medical Association 2007298 1429-1438. (doi:10.1001/jama.298.12.1429)

7 Klose M, Brennum J, Poulsgaard L, Kosteljanetz M, Wagner A \& Feldt-Rasmussen U. Hypopituitarism is uncommon after aneurysmal subarachnoid haemorrhage. Clinical Endocrinology 201073 95-101. (doi:10.1111/j.1365-2265.2010.03791.x)

8 Lammert A, Bode H, Hammes HP, Birck R, Fatar M, Zohsel K, Schmieder K, Schubert GA, Thome C \& Seiz M. Aneurysmal subarachnoid hemorrhage $(\mathrm{aSAH})$ results in low prevalence of neuro-endocrine dysfunction and NOT deficiency. Pituitary 2011 15 505-512. (doi:10.1007/s11102-011-0357-5)

9 Molitch ME, Clemmons DR, Malozowski S, Merriam GR, Vance ML \& Endocrine S. Evaluation and treatment of adult growth hormone deficiency: an Endocrine Society clinical practice guideline. Journal of Clinical Endocrinology and Metabolism 2011 96 1587-1609. (doi:10.1210/jc.2011-0179)

10 Ho KK. Consensus guidelines for the diagnosis and treatment of adults with GH deficiency II: a statement of the GH Research Society in association with the European Society for Pediatric 
Endocrinology, Lawson Wilkins Society, European Society of Endocrinology, Japan Endocrine Society, and Endocrine Society of Australia. European Journal of Endocrinology 2007157 695-700. (doi:10.1530/EJE-07-0631)

11 Tzanela M, Zianni D, Bilariki K, Vezalis A, Gavalas N, Szabo A, Drimala P, Vassiliadi D \& Vassilopoulos C. The effect of body mass index on the diagnosis of GH deficiency in patients at risk due to a pituitary insult. European Journal of Endocrinology 2009162 29-35. (doi:10.1530/EJE-09-0390)

12 van der Schaaf I, Algra A, Wermer M, Molyneux A, Clarke M, van Gijn J \& Rinkel G. Endovascular coiling versus neurosurgical clipping for patients with aneurysmal subarachnoid haemorrhage. Cochrane Database of Systematic Reviews 200519 CD003085.

13 McKenna SP, Doward LC, Alonso J, Kohlmann T, Niero M, Prieto L \& Wiren L. The QoL-AGHDA: an instrument for the assessment of quality of life in adults with growth hormone deficiency. Quality of Life Research $1999 \mathbf{8}$ 373-383. (doi:10.1023/ A:1008987922774)

14 Teasedale GM, Drake CG, Hunt W, Kassell N, Sano K, Pertuiset B \& De Villiers JC. A universal subarachnoid haemorrhage scale: report of a committee of the World Federation of Neurosurgical Societies. Journal of Neurology, Neurosurgery, and Psychiatry 1988 51 1457. (doi:10.1136/jnnp.51.11.1457)

15 Fisher CM, Kistler JP \& Davis JM. Relation of cerebral vasospasm to subarachnoid hemorrhage visualized by computerized tomographic scanning. Neurosurgery 19806 1-9. (doi:10.1227/ 00006123-198001000-00001)

16 Leong KS, Walker AB, Martin I, Wile D, Wilding J \& MacFarlane IA. An audit of 500 subcutaneous glucagon stimulation tests to assess growth hormone and ACTH secretion in patients with hypothalamic-pituitary disease. Clinical Endocrinology 200154 463-468. (doi:10.1046/j.1365-2265.2001.01169.x)

17 Corneli G, Di Somma C, Baldelli R, Rovere S, Gasco V, Croce CG, Grottoli S, Maccario M, Colao A, Lombardi G et al. The cut-off limits of the GH response to GH-releasing hormone-arginine test related to body mass index. European Journal of Endocrinology 2005 153 257-264. (doi:10.1530/eje.1.01967)

18 Littley MD, Gibson S, White A \& Shalet SM. Comparison of the ACTH and cortisol responses to provocative testing with glucagon and insulin hypoglycaemia in normal subjects. Clinical Endocrinology 198931 527-533. (doi:10.1111/j.1365-2265. 1989.tb01276.x)

19 Kokshoorn N, Wassenaar M, Biermasz N, Roelfsema F, Smit J, Romijn J \& Pereira A. Hypopituitarism following traumatic brain injury: the prevalence is affected by the use of different dynamic tests and different normal values. European Journal of Endocrinology 2009 162 11-18. (doi:10.1530/EJE-09-0601)

20 Lissett CA, Thompson EG, Rahim A, Brennan BM \& Shalet SM. How many tests are required to diagnose growth hormone (GH) deficiency in adults? Clinical Endocrinology $1999 \mathbf{5 1} 551-557$. (doi:10.1046/j.1365-2265.1999.00836.x)

21 Iranmanesh A, Lizarralde G \& Veldhuis JD. Age and relative adiposity are specific negative determinants of the frequency and amplitude of growth hormone (GH) secretory bursts and the half-life of endogenous GH in healthy men. Journal of Clinical Endocrinology and Metabolism 199173 1081-1088. (doi:10.1210/jcem-73-5-1081)

22 Kelestimur F, Popovic V, Leal A, Van Dam PS, Torres E, Perez Mendez LF, Greenman Y, Koppeschaar HP, Dieguez C \& Casanueva FF. Effect of obesity and morbid obesity on the growth hormone $(\mathrm{GH})$ secretion elicited by the combined GHRH + GHRP- 6 test. Clinical Endocrinology 2006 64 667-671. (doi:10.1111/ j.1365-2265.2006.02525.x)

23 Bonert VS, Elashoff JD, Barnett P \& Melmed S. Body mass index determines evoked growth hormone $(\mathrm{GH})$ responsiveness in normal healthy male subjects: diagnostic caveat for adult $\mathrm{GH}$ deficiency. Journal of Clinical Endocrinology and Metabolism 2004 89 3397-3401. (doi:10.1210/jc.2003-032213)

24 Cordido F, Alvarez-Castro P, Isidro ML, Casanueva FF \& Dieguez C. Comparison between insulin tolerance test, growth hormone
(GH)-releasing hormone (GHRH), GHRH plus acipimox and GHRH plus GH-releasing peptide- 6 for the diagnosis of adult GH deficiency in normal subjects, obese and hypopituitary patients. European Journal of Endocrinology 2003149 117-122. (doi:10.1530/eje.0.1490117)

25 Orme SM, Price A, Weetman AP \& Ross RJ. Comparison of the diagnostic utility of the simplified and standard i.m. glucagon stimulation test (IMGST). Clinical Endocrinology 199849 773-778. (doi:10.1046/j.1365-2265.1998.00610.x)

26 Rao RH \& Spathis GS. Intramuscular glucagon as a provocative stimulus for the assessment of pituitary function: growth hormone and cortisol responses. Metabolism 198736 658-663. (doi:10.1016/0026-0495(87)90150-8)

27 Conceicao FL, da Costa e Silva A, Leal Costa AJ \& Vaisman M. Glucagon stimulation test for the diagnosis of GH deficiency in adults. Journal of Endocrinological Investigation 200326 1065-1070.

28 Toogood A. Growth hormone tests: are they all the same? Hormone Research 200768 (Suppl 5) 66-67. (doi:10.1159/000110479)

29 Yuen KC, Biller BM, Molitch ME \& Cook DM. Clinical review: is lack of recombinant growth hormone (GH)-releasing hormone in the United States a setback or time to consider glucagon testing for adult GH deficiency? Journal of Clinical Endocrinology and Metabolism 200994 2702-2707. (doi:10.1210/jc.2009-0299)

30 Gomez JM, Espadero RM, Escobar-Jimenez F, Hawkins F, Pico A, Herrera-Pombo JL, Vilardell E, Duran A, Mesa J, Faure E et al. Growth hormone release after glucagon as a reliable test of growth hormone assessment in adults. Clinical Endocrinology 200256 329-334. (doi:10.1046/j.1365-2265.2002.01472.x)

31 Kreitschmann-Andermahr I, Hoff C, Saller B, Niggemeier S, Pruemper S, Hutter BO, Rohde V, Gressner A, Matern S \& Gilsbach JM. Prevalence of pituitary deficiency in patients after aneurysmal subarachnoid hemorrhage. Journal of Clinical Endocrinology and Metabolism 200489 4986-4992. (doi:10.1210/ jc.2004-0146)

32 Bellebaum C, Schafers L, Schoch B, Wanke I, Stolke D, Forsting M \& Daum I. Clipping versus coiling: neuropsychological follow up after aneurysmal subarachnoid haemorrhage (SAH). Journal of Clinical and Experimental Neuropsychology 200426 1081-1092. (doi:10.1080/13803390490515342)

33 Osterman PO. Hypothalamo-pituitary-adrenal function following subarachnoid hemorrhage. Acta Neurologica Scandinavica $1975 \mathbf{5 2}$ 56-62. (doi:10.1111/j.1600-0404.1975.tb02827.x)

34 Veldhuis JD, Iranmanesh A, Roelfsema F, Aoun P, Takahashi P, Miles JM \& Keenan DM. Tripartite control of dynamic ACTHcortisol dose responsiveness by age, body mass index, and gender in 111 healthy adults. Journal of Clinical Endocrinology and Metabolism 201196 2874-2881. (doi:10.1210/jc.2011-0084)

35 Crompton MR. Hypothalamic lesions following the rupture of cerebral berry aneurysms. Brain 196386 301-314. (doi:10.1093/ brain/86.2.301)

36 Bjerre P, Videbaek H \& Lindholm J. Subarachnoid hemorrhage with normal cerebral angiography: a prospective study on sellar abnormalities and pituitary function. Neurosurgery 198619 1012-1015. (doi:10.1227/00006123-198612000-00018)

37 Karaca Z, Tanriverdi F, Dagli AT, Selcuklu A, Casanueva FF, Unluhizarci K \& Kelestimur F. Three years prospective investigation of pituitary functions following subarachnoid haemorrhage. Pituitary, 2013. In press. (doi:10.1007/s11102-012-0377-9)

38 Gardner CJ, Javadpour M, Morgan C, Daousi C, Macfarlane IA \& Cuthbertson DJ. Hypopituitarism - a late consequence of aneurysmal subarachnoid haemorrhage? British Journal of Neurosurgery 201125 337-338. (doi:10.3109/02688697. 2010.546900)

Received 26 September 2012

Revised version received 05 December 2012

Accepted 05 December 2012 